\title{
Developmental change in the cross-modal Stroop effect
}

\author{
JULIE B. HANAUER and PATRICIA J. BROOKS \\ City University of New York, Staten Island, New York
}

\begin{abstract}
E. M. Elliott, Cowan, and Valle-Inclan (1998) reported a cross-modal Stroop-like interference effect in adults when an auditory distractor (a color or noncolor word) occurred simultaneously with a color patch to be named. Response times were slower with color as opposed to noncolor distractors. To distinguish two accounts of this phenomenon, we tested 4- to 11-year-olds and adults. The suppression hypothesis posits that the irrelevant word enters a phonological buffer and is injurious to color naming if the participant is unable to suppress its representation in time. The concurrent processing hypothesis states that interference occurs when the distractor and the color name are lexically accessed at the same time. Our finding that the cross-modal Stroop effect occurred in young children even with a distractor presented $500 \mathrm{msec}$ in advance of the color patch favors the suppression account. Development in executive functioning may also contribute to the interference effect's becoming progressively weaker with age.
\end{abstract}

The Stroop color word task (Stroop, 1935) is perhaps the most well-known measure of selective attention. Selective attention is the ability to focus on one particular aspect of a stimulus while defocusing other aspects of the same stimulus (Bedi, Halperin, \& Sharma, 1994). In the Stroop task, participants are asked to name the print color of a color word (e.g., say "red" when shown the word blue printed in red). A correct response requires participants to inhibit reading the color word, a task that is difficult because there is a strong tendency to read the word itself, rather than identify its print color. Individuals must selectively attend to the print color and inhibit reading the word. According to one account (MacLeod, 1991), it takes a greater amount of time to state the print color of a color word, in comparison with a nonword or a noncolor word, because reading is not entirely under conscious control; therefore, what is read competes with the print color to be named.

A number of researchers have modified the Stroop procedure to see whether the interference effect is present in other modalities besides the visual modality. For example, in Green and Barber (1981, 1983), significant interference occurred in the auditory modality when participants were instructed to say "girl" if the speaker was

A portion of this paper was presented at 41 st Annual Meeting of the Psychonomic Society, New Orleans, November 2000. The authors thank the children who participated in the study and their parents. We thank Devin Bracco, Jose Colon, Peter Hanauer, Stephanie Landolfi, Maya McLawrence, and Barbara Padowska for assistance with data collection and analysis and Nelson Cowan for his helpful review of the manuscript. Please address correspondence to P. J. Brooks, Department of Psychology,4S-1 12, the College of Staten Island of the City University of New York, 2800 Victory Blvd., Staten Island, NY 10314 (e-mail: pbrooks@postbox.csicuny.edu). male and "boy" if the speaker was female. Cowan and colleagues (Cowan, 1989; Cowan \& Barron, 1987; E. M. Elliott, Cowan, \& Valle-Inclan, 1998) designed a crossmodal Stroop analogue with colors presented in the visual modality and words presented over headphones. They found significantly slower color-naming latencies when colors were paired with color word distractors (e.g., seeing purple and hearing yellow), as compared with noncolor words (e.g., seeing purple and hearing single). Cowan and Barron argued that adults could not fully inhibit the processing of words in the auditory modality and, therefore, could not limit lexical processing to the visual modality. This claim, however, became controversial, since Miles and Jones (1989) and Miles, Madden, and Jones (1989) failed to replicate Cowan and Barron. Cowan (1989), E. M. Elliott et al. (1998), and E. M. Elliott and Cowan (2001) claimed that the failed replications were due to methodological errors and again demonstrated the cross-modal Stroop effect.

The debate over the existence of the cross-modal Stroop effect is of theoretical importance in determining the constraints on the role of working memory in language processing. According to the influential theory of Baddeley $(1986,1997)$, the phonological loop is a component of verbal working memory responsible for the temporary storage of sound patterns. Miles et al. (1989) argued that when verbal material is being maintained in the phonological loop, interference might occur if an item to be remembered is displaced by another item that enters this temporary store. Interference in the phonological loop is most likely to occur if the phonological loop's capacity has been reached and the displacing item is phonologically similar (as opposed to semantically related) to the item to be remembered. Hence, Miles et al. did not expect there to be a cross-modal Stroop effect, because 
the task does not require participants to maintain words in the phonological loop over any period of time and, second, on any trial, the distractor is not phonologically related to the target color name. Cowan and Barron (1987) argued for a broader view of the phonological loop as a temporary speech buffer where words to be spoken may be held prior to articulation. When there are multiple items in this temporary store, selection of the item most relevant to the task at hand must occur, and there may be competition among candidate items, even in cases in which the words are not phonologically related. In the cross-modal Stroop task, the auditory distractor automatically enters the temporary speech buffer as it is processed. Because it takes time to trace the origin of each item in the buffer when one selects the name of the color patch as the intended word to be produced, interference occurs in color naming. As the semantic relatedness of the words in the buffer increases, the ease of selecting the correct word decreases, leading to greater interference with color word distractors than with noncolor word distractors.

In the E. M. Elliott et al.'s (1998) study, the timing of presentation of the color patch to be named and of the distractor was varied by presenting the distractor either simultaneously with or $500 \mathrm{msec}$ prior to the presentation of the color. Exposure to a word $500 \mathrm{msec}$ before presentation of a visual stimulus provides sufficient time to allow for complete processing of the word (Baddeley, 1986; Cowan \& Saults, 1995). Thus, with the distractor presented $500 \mathrm{msec}$ before the color patch, E. M. Elliott et al. predicted a cross-modal Stroop effect, because the auditory representation of the word would still be active in working memory. Surprisingly, they found the predicted interference effect only with simultaneous presentation of the color patch and the distractor. E. M. Elliott et al. considered two possible explanations. First, delaying the presentation of the color patch by $500 \mathrm{msec}$ might provide participants with sufficient time to both process and suppress activation of the distractor. Alternatively, the cross-modal Stroop effect might stem from concurrent lexical access of the words presented in the auditory and the visual modalities. This hypothesis derives from a study by Schriefers, Meyer, and Levelt (1990), in which they showed semantic interference in a cross-modal pictureword interference paradigm. Schriefers et al. suggested that semantic interference stems from competition between the distractor and the picture names, occurring during the semantically driven stage of lexical access, called lemma retrieval. Although E. M. Elliott et al. favored the former, suppression account as an explanation of the time course of the cross-modal Stroop effect, their data do not provide a basis for ruling out the alternative concurrent processing explanation.

We propose that examining the development of the cross-modal Stroop effect will help to resolve the controversies regarding the source and reliability of the interference effect because developmental differences in selective attention may affect the time course and mag- nitude of the effect. In developmental studies of the visual Stroop effect, the interference effect has been shown to decline in magnitude from the age of 7 years to early adulthood (Comalli, Wapner, \& Werner, 1962; Rosinski, Golinkoff, \& Kukish, 1975). Not surprisingly, in children who are not yet skilled readers, the effect does not occur at all (Ehri, 1976; Schiller, 1966). To study development of selective attention and inhibition in very young children, researchers have modified the methodology of the Stroop task in a variety of ways. For instance, Gerstadt, Hong, and Diamond (1994) designed a day-night Stroop task in which 3- to 7-year-olds were instructed to say "day" when shown a line drawing of moon and stars and "night" when shown a line drawing of the sun. That is, in the experimental condition, the correct answer was the opposite of what the card depicted. In a control condition, children were instructed to say "day" and "night" in response to specific abstract geometric patterns. Although even the youngest children performed well in the control condition, in the experimental condition children younger than 5 years of age often took very long to respond and made many errors. Gerstadt et al. concluded that the younger children could not remember the rules of the game while inhibiting the matching response (i.e., saying "night" when shown the moon and stars). Jerger and her colleagues (Jerger, Martin, \& Pirozzolo, 1988; Jerger, Pearson, \& Spence, 1999) modified Green and Barber's $(1981,1983)$ auditory Stroop task for use with preschoolers. In Jerger et al. (1988), 3- to 6-year-olds were told to press a Mommy button whenever a male voice was heard and a Daddy button whenever a female voice was heard. Jerger et al. (1988) found slower response latencies for conflict trials (e.g., hearing $d a d d y$ spoken in a female voice), as compared with either congruent trials (e.g., hearing mommy spoken in a female voice) or neutral trials (e.g., hearing ice cream spoken in either voice). Furthermore, the magnitude of the interference effect (i.e., the reaction time [RT] difference between conflict and neutral conditions) decreased significantly between the ages of 3 and 4 . Taken together, these studies have shown development in selective attention, leading to a decrease in Stroop-like interference, but have not addressed the specific issue of the independence of lexical processing in the auditory and the visual modalities. To our knowledge, no previous research has compared the extent to which children and adults are able to suppress processing of irrelevant spoken words when naming visually presented stimuli.

In the present study, we examined the development of the cross-modal Stroop effect in 4- to 11-year-old children and adults. Given the inconsistency of reports of the effect, we adopted the basic procedures of E. M. Elliott et al. (1998, Experiment 1) to maximize the likelihood of replicating their results with adults. However, we varied the timing of the distractor relative to the picture somewhat differently than in E. M. Elliott et al. to provide a stronger test of the suppression and concurrent processing explanations of the effect. We present two timing 
conditions. The first is an exact replication of the 0 -msec (simultaneous) condition of E. M. Elliott et al. (1998), at which they found a reliable cross-modal Stroop effect in adults. However, because of developmental differences in processing speed (Kail, 1991, 1992), for the -500 -msec condition, we lengthened the interval between presentation of the distractor and the color patch to provide children with sufficient time to fully process the word prior to seeing the patch. That is, we increased the stimulus asynchrony (SA) to rule out the possibility of concurrent lexical access of the distractor and the color name even in our youngest participants. In our experiment, the color patch appeared $500 \mathrm{msec}$ after the offset of the word, as opposed to $500 \mathrm{msec}$ after the onset, as in E. M. Elliott et al. This manipulation of SA allows us to evaluate the competing accounts of the cross-modal effect proposed by E. M. Elliott et al.

If the concurrent lexical processing account is correct, we would expect the interference effect to occur only with simultaneous presentation of the color patch and the distractor, irrespective of the age of the participant. However, if the suppression account is correct, we would expect to observe the interference effect at both timing conditions in young children, owing to their requiring more time to process and inhibit the distracting words. Furthermore, owing to a developmental progression in the ability to selectively attend to color naming while inhibiting irrelevant auditory distractors, we would predict that the cross-modal Stroop effect would be robust in children and become progressively weaker with age. That is, we would suspect that the relatively small interference effect observed in previous studies with adults is the end point of a trajectory in the development of selective attention.

\section{METHOD}

\section{Participants}

Fifteen 4 - to 5 -year-olds ( 6 boys, 9 girls; mean age, 4 years 11 months; range, 4 years 1 month to 5 years 11 months), fifteen 6 to 7 -year-olds ( 7 boys, 8 girls; mean age, 6 years 11 months; range, 6 years 2 months to 7 years 8 months), fifteen 9 - to 11 -year-olds ( 9 boys, 6 girls; mean age, 10 years 6 months; range, 9 years 1 month to 11 years 11 months), and 30 undergraduates (14 men, 16 women; mean age, 22 years; range, 17-34 years) took part in the study. All the participants had corrected-to-normal vision and normal hearing and were prescreened to ensure no color perception deficiencies. The sample was ethnically diverse and predominantly of middleclass background. The children were recruited using flyers posted at the College of Staten Island of the City University of New York. They were tested in a psychology laboratory and received stickers and $\mathrm{t}$-shirts for their participation. The undergraduates were recruited from introductory psychology classes and received extra credit for their efforts. In the adult group, we tested twice the number of participants than in the child groups, owing to the small effect sizes obtained in previous studies (Cowan \& Barron, 1987; E. M. Elliott et al., 1998).

\section{Apparatus and Stimuli}

The experiment was conducted using a Macintosh Power PC computer equipped with PsyScope experimental software (Cohen, MacWhinney, Flatt, \& Provost, 1993) and SoundEdit 16. The visual stimuli consisted of six color patches, measuring $3 \times 3$ in., surrounded by a black background. The colors were red, white, blue, green, yellow, and purple, as in E. M. Elliott et al. (1998). Spoken words corresponding to the six colors, along with six noncolor words (dry, single, real, short, fewer, and best), were presented over headphones in a naturally spoken female voice. The noncolor words were matched to the color words in terms of word frequency and syllable structure (Carroll, Davies, \& Richman, 1971; Elliott et al., 1998). The duration of the color words ranged from 315 to $512 \mathrm{msec}$, with a mean of $411 \mathrm{msec}$, and the duration of the noncolor words ranged from 308 to $496 \mathrm{msec}$, with a mean of $410 \mathrm{msec}$. The PsyScope software controlled the presentation of the spoken words and color patches. Each stimulus picture was paired with every stimulus word except its own (e.g., the red color patch was never paired with the word red). That is, in each block of trials, items were randomly selected with replacement from a list combining each color patch with each color word (except for the matching color word) and each noncolor word. A microphone was set up in front of the participant, with a voice key triggering a button box timer that recorded response latencies for color naming. RTs for correct responses were measured from the onset of the color patch to the triggering of the voice key by the participant's response.

\section{Procedure}

Each participant was tested individually in a quiet room. The participants were seated in front of the computer monitor, with a microphone adjusted to be approximately $1 \mathrm{in}$. away from their mouth. Six color patches (red, blue, white, green, purple, and yellow), printed on white paper from a color printer, were shown to the participant as the experimenter read the color names aloud. The participant was then asked to repeat the color words to ensure color recognition. The participants then were told that they were going to play a computer game and were asked to wear a set of headphones. The participants were told that the object of the game was to "say what you see." The experimenter said, "In this game, color patches are going to appear on the screen and your job is to name the colors as quickly as possible. Sometimes, you are going to hear words over the headphones, but try your best to ignore the word and say only what you see. The words may confuse you sometimes because they may be different from what you see, but you should concentrate and say what you see." The participants were told to name the color of each color patch as soon as it appeared, and not to talk otherwise. After 36 trials, a smiley face appeared to indicate that the block of trials was finished. At the end of each block, the participants were told that they did a great job, and the children received stickers for their efforts.

Each trial began with a white fixation cross, which remained on the screen for $2,500 \mathrm{msec}$. In the 0 -msec condition, the timing of the onset of the auditory distractor was simultaneous with presentation of the color patch and coincided with the disappearance of the fixation cross. In the $-500-m s e c$ condition, the timing of the onset of the auditory distractor was simultaneous with the disappearance of the fixation cross, and the color patch appeared $500 \mathrm{msec}$ after the offset of the word. In the silent condition, the color patch replaced the fixation cross after $2,500 \mathrm{msec}$, and no auditory distractor occurred. The participant's response activated a voice key that recorded the RT for the trial and triggered the disappearance of the color patch. After $200 \mathrm{msec}$, the fixation cross for the next trial appeared. The experimenter kept a log of the participants' responses as a record of errors and lost trials.

Each participant received five blocks of trials. The first block consisted of 18 trials of the silent condition. This allowed the participants to practice naming the color patches as they appeared on the computer monitor and allowed the experimenter to adjust the sensitivity of the voice key. If the participants made any errors during this block (i.e., misnaming a color patch), they were corrected. The second block comprised 18 practice trials with auditory distractors to allow the participant to get used to hearing the words in 
the headphones. If the participants made any errors in this block (e.g., repeating the auditory stimulus instead of naming the color patch), they were corrected. After the two blocks of practice trials, three blocks of 36 test trials (108 total trials) were presented with each block, consisting of 12 silent trials, 12 color word trials (6 at each SA), and 12 noncolor word trials (6 at each SA), occurring in a random order. In the test blocks, the participants were not corrected for any errors. If, at any point during the experiment, a child became distracted or started a conversation, the experimenter paused the experiment until the child calmed down and trials could be resumed.

\section{RESULTS}

\section{Reaction Times}

Since the distributions of RTs were positively skewed, especially for the youngest children, who often took very long to respond, we used median RTs for correct trials as the dependent variable. Table 1 presents median RTs for each age group as a function of distractor type and SA. Overall, color naming was fastest for the $-500-\mathrm{msec}$ condition, intermediate for the silent condition, and slowest for the 0 -msec condition. This ordering of RTs as a function of distractor condition exactly replicated Elliott et al. (1998) and was likely due to the fact that the timing of the color patch, relative to both the fixation point and the distractor, varied randomly across trials within each block. Thus, because it was impossible to predict for any trial exactly when the color patch would appear, when the distractor preceded the color patch $(-500-\mathrm{msec}$ SA), it alerted the participant to prepare a response. In the following statistical analyses, we will examine RTs for trials involving auditory distractors and will not consider the silent condition further.

RTs were analyzed in a mixed design analysis of variance (ANOVA) with SA ( -500 or $0 \mathrm{msec}$ ) and distractor type (color word or noncolor word) as within-subjects factors and age (4- to 5-year-olds, 6- to 7-year-olds, 9- to 11 -year-olds, or adults) as a between-subjects factor. ${ }^{1}$ The dependent variable was the median RT for naming the color patches. The ANOVA showed main effects of age $\left[F(3,71)=48.98, M S_{\mathrm{e}}=265,525, p<.001\right]$, accounting for $50 \%$ of the total variance, distractor type $\left[F(1,71)=40.30, M S_{\mathrm{e}}=28,871, p<.001\right]$, accounting for $2 \%$ of the variance, and SA $\left[F(1,71)=184.18, M S_{\mathrm{e}}=\right.$
$41,516, p<.001]$, accounting for $10 \%$ of the variance. Overall RTs for naming colors decreased markedly with age. RTs tended to be faster for noncolor word trials than for color word trials and were faster when the distractor occurred in advance of the color patch (-500-msec SA) rather than simultaneously with the color patch $(0-\mathrm{msec}$ $\mathrm{SA})$. The main effects were qualified by significant twoway interactions of age with distractor type $[F(3,71)=$ $\left.13.10, M S_{\mathrm{e}}=28,871, p<.001\right]$, accounting for $2 \%$ of the variance, age with SA $\left[F(3,71)=27.43, M S_{\mathrm{e}}=\right.$ $41,516, p<.001]$, accounting for $4 \%$ of the variance, and distractor type with SA $\left[F(1,71)=11.80, M S_{\mathrm{e}}=16\right.$, $613, p<.001]$, accounting for less than $1 \%$ of the variance. The three-way interaction of age, distractor type, and SA was not significant.

To test for the existence of a cross-modal Stroop effect at each age, planned comparisons were conducted, comparing RTs for color word and noncolor word trials at each SA condition. For the $-500 \mathrm{SA}$ condition, the 4 - to 5 -year-olds named color patches paired with color words more slowly than color patches paired with noncolor words $\left[F(1,14)=9.45, M S_{\mathrm{e}}=57,335, p<.01\right]$, accounting for $2 \%$ of the total variance. In contrast, for the other age groups, RTs for color word and noncolor word trials were statistically equivalent when the distractor was presented $500 \mathrm{msec}$ before the color patch. Thus, for all groups except the youngest children, delaying presentation of the color patch by $500 \mathrm{msec}$ provided sufficient time for activation of the distractor to be fully suppressed. The lack of a cross-modal Stroop effect in adults with the distractor presented in advance of the color patch replicated the findings of Elliott et al. (1998). For the 0 -msec SA condition, the RT difference for color word and noncolor word trials was highly significant for the 4- to 5-year-olds $\left[F(1,14)=20.38, M S_{\mathrm{e}}=57,335\right.$, $p<.001]$, accounting for $5 \%$ of the variance, and for the 6- to 7-year-olds $\left[F(1,14)=33.40, M S_{\mathrm{e}}=11,098, p<\right.$ $.001]$, accounting for $5 \%$ of the variance, and was reliable for the 9 - to 11 -year-olds $\left[F(1,14)=5.13, M S_{\mathrm{e}}=\right.$ $12,982, p<.05$ ], accounting for $2 \%$ of the variance, and for the adults $\left[F(1,29)=6.09, M S_{\mathrm{e}}=1,369, p<.05\right]$, accounting for less than $1 \%$ of the variance. Taken together, the planned comparisons show that the crossmodal Stroop effect is much more robust in children than

Table 1

Median Reaction Times (in Milliseconds, With Standard Errors) as a Function of Auditory Stimulus Condition (Stimulus Asynchrony [SA] and Distractor Type) and Participant Age

\begin{tabular}{|c|c|c|c|c|c|c|c|c|c|c|}
\hline \multirow[b]{4}{*}{ Age } & \multicolumn{10}{|c|}{ Auditory Stimulus Condition } \\
\hline & & & \multicolumn{4}{|c|}{-500 -msec SA } & \multicolumn{4}{|c|}{0 -msec SA } \\
\hline & \multicolumn{2}{|c|}{ Silent } & \multicolumn{2}{|c|}{ Color Word } & \multicolumn{2}{|c|}{$\overline{\text { Noncolor Word }}$} & \multicolumn{2}{|c|}{ Color Word } & \multicolumn{2}{|c|}{$\overline{\text { Noncolor Word }}$} \\
\hline & Median & $\overline{S E}$ & Median & $\overline{S E}$ & Median & $\overline{S E}$ & $\overline{\text { Median }}$ & $\overline{S E}$ & Median & $\overline{S E}$ \\
\hline $4-5$ years & 1,481 & 132 & 1,361 & 162 & 1,092 & 78 & 2,015 & 197 & 1,620 & $\overline{123}$ \\
\hline $6-7$ years & 1,096 & 65 & 962 & 49 & 913 & 41 & 1,495 & 98 & 1,273 & 62 \\
\hline $9-11$ years & 770 & 33 & 680 & 25 & 675 & 22 & 970 & 69 & 875 & 49 \\
\hline Adult & 597 & 22 & 557 & 13 & 571 & 15 & 630 & 29 & 606 & 25 \\
\hline
\end{tabular}

Note $-N=15$ for each child group; $N=30$ for adults. 
in adults and occurs at a wider range of SA conditions in very young children than in older children and adults.

Finally, we examined proportional RT differences when a color word distractor occurred, in comparison with a noncolor word distractor. These proportions were computed by dividing RT differences between color and noncolor distractor conditions by RTs for the noncolor distractor condition. For the $-500-\mathrm{msec}$ SA condition, the proportional differences were $24.6 \%$ for the 4 - to 5 year-olds, $5.4 \%$ for the 6 - to 7 -year-olds, $0 \%$ for the 9 to 11 -year-olds, and $2.5 \%$ (in the opposite direction) for the adults. For the $0-\mathrm{msec} S \mathrm{~S}$ condition, the proportional differences were $24.4 \%$ for the 4 - to 5 -year-olds, $17.4 \%$ for the 6- to 7 -year-olds, $10.9 \%$ for the 9 - to 11 -yearolds, and $4.0 \%$ for the adults. Thus, we see further evidence of the decline in the effect size of the interference effect with age.

\section{Errors}

Table 2 presents error rates for each age group as a function of distractor type and SA. Trials were counted as errors when the participant misnamed the color patch (e.g., seeing the color green, but saying "yellow"). If a participant stuttered (e.g., by saying "ah" prior to naming the color), failed to make a response within $7 \mathrm{sec}$, or did not speak loudly enough for the voice key to activate, or if the voice key was triggered prematurely (e.g., by heavy breathing in the direction of the microphone or kicking or hitting the desk), the trial was considered lost. Of the 108 total test trials, the 4- to 5-year-olds averaged 5.7 lost trials, the 6- to 7-year-olds averaged 1.9 lost trials, the 9- to 11-year-olds averaged 1.8 lost trials, and the adults averaged 1.4 lost trials. Error rates were computed as proportions of completed trials, taking into consideration the number of lost trials for each condition.

Errors were analyzed in a mixed design ANOVA with within-subjects factors of SA $(-500$ or $0 \mathrm{msec})$ and distractor type (color word or noncolor word) and a betweensubjects factor of age (4- to 5-year-olds, 6- to 7-yearolds, 9- to 11-year-olds, or adults). Error proportions were arcsine transformed prior to statistical analysis, as is recommended for proportional data (Cohen \& Cohen, 1983). Overall, the main effect of age was significant $\left[F(3,71)=11.69, M S_{\mathrm{e}}=0.10, p<.001\right]$, and accounted for $16 \%$ of the total variance. Although error rates were relatively low at all ages, there was a significant decline in errors with age. The only other significant effect in the ANOVA was a two-way interaction of distractor type and SA $\left[F(1,71)=5.24, M S_{\mathrm{e}}=0.05, p<.05\right]$, accounting for $1 \%$ of the variance. When the distractor occurred simultaneously with the color patch (0-msec SA), the error rate for color word trials was significantly higher than that for noncolor word trials $[F(1,71)=4.91$, $\left.M S_{\mathrm{e}}=0.05, p<.05\right]$. At the -500 -msec SA, error rates for color word and noncolor word trials were statistically equivalent. Planned comparisons of error rates for color word and noncolor word trials were conducted for each age group separately but revealed no significant differences, owing to low error rates and low statistical power.

\section{DISCUSSION}

In this study, we examined the development of selective attention, using the cross-modal Stroop task, testing children 4-11 years of age as well as adults. Prior studies of selective attention (e.g., Dempster, 1992; Lane \& Pearson, 1982; Zelazo, Carter, Reznick, \& Frye, 1997) have demonstrated that the ability to tune out distracting information and suppress inappropriate action develops throughout childhood and adolescence. These studies have not specifically addressed the issue of whether one can ignore irrelevant spoken language while selectively attending to a visual stimulus. The cross-modal Stroop task proved to be an ideal measure for this purpose, in that it enabled us to test individuals of a wide range of ages, using identical procedures. We discovered that interference from hearing of irrelevant color words while one is naming colors decreased markedly with age. Thus, although noisy environments have been shown to disrupt adult work performance (Banbury \& Berry, 1998), our results suggest that children may be even more drastically affected, for instance, by irrelevant spoken language from television or adult conversation.

It is of interest that, in our pilot work with eight 3year-olds, we found that the majority of children at this age could not perform the cross-modal Stroop task at all. In the practice condition, when asked to name the color patches in the absence of auditory distractors, the 3-yearolds performed accurately. However, when the distractors were presented along with the color patches, all but

Table 2

Mean Percentages of Errors (with Standard Errors) as a Function of Auditory Stimulus Condition (Stimulus Asynchrony [SA] and Distractor Type) and Participant Age

\begin{tabular}{|c|c|c|c|c|c|c|c|c|c|c|}
\hline \multirow[b]{4}{*}{ Age } & \multicolumn{10}{|c|}{ Auditory Stimulus Condition } \\
\hline & & & \multicolumn{4}{|c|}{$-500-\mathrm{msec} \mathrm{SA}$} & \multicolumn{4}{|c|}{0 -msec SA } \\
\hline & \multicolumn{2}{|c|}{ Silent } & \multicolumn{2}{|c|}{ Color Word } & \multicolumn{2}{|c|}{ Noncolor Word } & \multicolumn{2}{|c|}{ Color Word } & \multicolumn{2}{|c|}{ Noncolor Word } \\
\hline & $M$ & $S E$ & $M$ & $S E$ & $M$ & $S E$ & $M$ & $S E$ & $M$ & $S E$ \\
\hline $4-5$ years & 2.7 & 1.0 & 5.1 & 1.9 & 4.0 & 1.4 & 8.2 & 2.5 & 6.5 & 2.7 \\
\hline $6-7$ years & 2.9 & 0.8 & 1.1 & 0.7 & 3.3 & 1.0 & 4.3 & 1.4 & 1.9 & 1.2 \\
\hline $9-11$ years & 1.5 & 0.8 & 0.9 & 0.6 & 1.0 & 0.6 & 1.9 & 1.1 & 0.8 & 0.5 \\
\hline Adult & 1.5 & 0.5 & 0.7 & 0.4 & 0.3 & 0.2 & 1.0 & 0.5 & 0.7 & 0.4 \\
\hline
\end{tabular}

Note- $N=15$ for each child group; $N=30$ for adults. 
2 of the children consistently repeated the words they had heard, even though they knew that the rules were to "say what you see." Only these 2 children were able to complete a single block of 36 test trials and produced only $28 \%$ and $40 \%$ correct responses for this block. Attempts to train the 3-year-olds to ignore the spoken words while naming the color patches led to child frustration and forced us to abandon testing younger children. Clearly, the auditory modality was highly salient and nearly impossible for our youngest participants to ignore. In comparison with the 3-year-olds, none of the 4 - to 5 -year-olds produced errors in over $20 \%$ of the trials with distractors, and only 3 children had error rates over $10 \%$.

Our discovery of a developmental trajectory in performance of the cross-modal Stroop task helps to clarify the literature on the effect. With only adults being tested in previous cross-modal Stroop experiments, some researchers have found reliable interference (Cowan, 1989; Cowan \& Barron, 1987; E. M. Elliott \& Cowan, 2001; E. M. Elliott et al., 1998), whereas others have not (Miles \& Jones, 1989; Miles et al., 1989). What is most pronounced in our data is the finding that the cross-modal Stroop effect becomes progressively weaker with development and is a relatively small effect in adults. The fact that a robust cross-modal Stroop effect appears when children are tested runs counter to Miles and his colleagues' assertion that interference from irrelevant spoken words occurs only in tasks involving short-term memory.

E. M. Elliott et al. (1998) considered two explanations of the cross-modal Stroop effect. They argued that semantic interference might occur in a temporary speech buffer unless there is sufficient time for the spoken word to be suppressed. Consistent with this hypothesis was their observation that the cross-modal Stroop effect fully disappeared in adults if the auditory distractor was presented $500 \mathrm{msec}$ in advance of the color patch. E. M. Elliott et al., however, could not rule out an alternative hypothesis that the cross-modal Stroop effect stems from concurrent lexical processing in the auditory and the visual modalities (Schriefers et al., 1990). According to the concurrent processing account, the interference effect occurs when there is temporal overlap in accessing the lemmas for the spoken word and name of the color patch and stems from competition among lemmas during lexical access.

To test these two accounts, we varied the timing of presentation of the auditory distractor, relative to presentation of the color patch. We hypothesized that the cross-modal Stroop effect would be seen over a wider range of SA in children than in adults, owing to differences in information-processing speed (Kail, 1991, 1992), coupled with less efficient suppression mechanisms (Bjorklund \& Harnishfeger, 1990; Livesey \& Morgan, 1991; Tipper, Bourque, Anderson, \& Brehaut, 1989). In one condition, the color patch occurred simultaneously with the distractor. With simultaneous presentation, both suppression and concurrent processing ac- counts would predict a cross-modal Stroop effect to occur, replicating E. M. Elliott et al. (1998). In the other condition, the color patch was delayed and appeared $500 \mathrm{msec}$ after the offset of the distractor. We suspected that a -500 -msec stimulus offset interval would be sufficient to prevent temporal overlap in lexical access for the auditory distractor and the color patch. Thus, the occurrence of a cross-modal Stroop effect, even in the youngest children, would be inconsistent with the concurrent processing account. Our results favored the suppression account: Our youngest participants showed a large interference effect at both SAs, whereas older participants showed interference only with simultaneous presentation of the distractor and the color patch. Thus, delaying presentation of the color patch by $500 \mathrm{msec}$ provided older children and adults, but not younger children, with sufficient time to fully suppress the irrelevant stimulus.

One possible objection to this interpretation of our results is that, given the relative inefficiency of word retrieval processes in children, a -500 -msec SA might not be sufficiently long to prevent simultaneous lexical activation of the distractor and the color patch names in very young children. Under normal listening conditions, lexical access occurs rapidly, even in young children. This has been shown in recent on-line studies of the development of word recognition, indicating that children as young as 24 months of age access the meanings of familiar spoken words prior to their offsets (Fernald, Pinto, Swingley, Weinberg, \& McRoberts, 1998; Swingley, Pinto, \& Fernald, 1999). Word recognition based on partial input has been observed in 24-month-olds even when the words in the response set share initial consonants, as in doll and doggie (Swingley et al., 1999). In gating studies examining word recognition for the larger vocabularies characteristic of school-aged children, L. L. Elliott, Hammer, and Evan (1987) and Walley, Michela, and Wood (1995) demonstrated that 5- to 7-year-olds readily identify words on the basis of partial input. For example, Walley et al. estimated that kindergartners (mean age, 6 years) isolated target words after hearing only $66 \%$ of the sound pattern (i.e., for words with an average length of $617 \mathrm{msec}$, the words were identified at $406 \mathrm{msec}$ ). Although informative, these research findings unfortunately do not indicate how long lexical activation lingers in the developing system. Thus, it is impossible for us to guarantee that in the cross-modal Stroop task, where participants could use the distractor as a cue to anticipate the onset of the color patch, there would be no temporal overlap in lexical activation of the target and the distractor names.

The suppression account of the cross-modal Stroop effect is supported by related findings in the developmental literature on the phenomenon of negative priming. Negative priming occurs when a participant must respond to a stimulus that was to be ignored on the preceding trial. Suppose, for example, in the original Stroop task, that on Trial 1 a participant saw the word blue printed in green 
and on Trial 2, he or she saw the word red printed in blue. Identifying blue as the print color on Trial 2 would take longer than it would if it had not been the ignored stimulus in the previous trial. It has been argued (e.g., Driver \& Baylis, 1993; Neill, 1977; Neill \& Westberry, 1987; Tipper et al., 1989) that the magnitude of the negative priming effect is a direct reflection of the efficiency of suppression mechanisms and is negatively correlated with susceptibility to distraction. Tipper et al. proposed that the developmental differences seen in studies of selective attention (e.g., Doyle, 1973; Gerstadt et al., 1994; Jerger et al., 1988; Zuckier \& Hagan, 1978) are due to children's underutilization of the suppression mechanism. In support of this idea, Tipper et al. observed that 7- to 8-year-olds showed greater Stroop interference than did adults and that adults showed greater negative priming than did 7- to 8 -year-olds. Driver and Baylis found similar tradeoffs in adults between the magnitude of the interference effect and the size of the negative priming effect in a cross-modal Stroop-like paradigm. It is noteworthy in this regard that Gernsbacher and her colleagues (e.g., Gernsbacher \& Faust, 1991; Gernsbacher, Varner, \& Faust, 1990) have observed that the efficiency of suppression mechanisms varies considerably among adults and is a strong predictor of individual differences in general comprehension skill (Gernsbacher, 1997). For example, less skilled comprehenders have been shown to less efficiently suppress inappropriate meanings of homophones (e.g., reject CALM after reading He had a lot of patients), as well as information across pictorial and printed word modalities (i.e., ignore words superimposed on pictures or pictures superimposed on words). These findings led us to predict that less skilled comprehenders would experience greater interference in the cross-modal Stroop task, at a wider range of SAs, than would more skilled comprehenders.

It is also important to note that recent studies (Brooks \& MacWhinney, 2000; Brooks, MacWhinney, \& Evans, 1995), using the cross-modal picture-word interference paradigm, have demonstrated, in both children and adults, that related words presented in the auditory modality can prime (i.e., facilitate), as well as inhibit, picture-naming latencies. Brooks et al. examined associative priming at a range of SAs, and found that picture-naming latencies for pictures paired with associated words (e.g., hearing cat when shown a picture of a dog) were significantly faster than latencies for pictures paired with unrelated words. This effect was robust in children and adults, even with the auditory stimulus occurring $550 \mathrm{msec}$ in advance of the picture. Thus, participants did not suppress activation of auditory stimuli that were potentially relevant to the task at hand. Together with the present study, Brooks et al.'s results indicate that suppression is a flexible, nonobligatory process that may be invoked under conditions in which it is beneficial, with developmental change occurring in the efficiency and flexibility of the underlying mechanisms.

In addition to development in suppression, other executive factors likely contributed to the failures of selective attention observed in the cross-modal Stroop task.
Executive skills essential for purposeful goal-directed activity, such as planning and monitoring action, selfregulation, impulse control, holding goals in active memory, maintaining proper response sets, and making use of feedback (Anderson, 1998; Gnys \& Willis, 1991), are thought to be mediated by the frontal cortex and the prefrontal cortex, which are the slowest maturing areas in the brain (Anderson, 1998; Bell \& Fox, 1992; Chugani, Mazziotta, \& Phelps, 1993). Researchers (e.g., Diamond \& Taylor, 1996; Gnys \& Willis, 1991; Levin et al., 1991; Passler, Isaac, \& Hynd, 1985; Zelazo et al., 1997) have used such tasks as the Tower of London, the Wisconsin Card Sorting Task, the go-no-go task, and delayed alternation to study developmental change in semantic associations, concept formation, mental flexibility, planning, and problem solving. We would argue that development in executive functioning greatly affects children's ability to play experimental games properly and most likely influenced performance on the cross-modal Stroop task.

\section{REFERENCES}

Anderson, V. (1998). Assessing executive function in children: Biological, psychological, and developmental considerations. Neuropsychological Rehabilitation, 8, 319-349.

BAdDeley, A. (1986). Working memory. Oxford: Oxford University Press.

BAdDeley, A. (1997). Human memory: Theory and practice. Boston: Allyn \& Bacon.

BAnbury, S., \& BERry, D. C. (1998). Disruption of office-related tasks by speech and office noise. British Journal of Psychology, 89, 499-517.

Bedi, G., Halperin, J. M., \& Sharma, V. (1994). Investigation of modality specific distractibility in children. International Journal of Neuroscience, 74, 79-85.

Bell, M. A., \& Fox, N. A. (1992). The relations between frontal brain electrical activity and cognitive development during infancy. Child Development, 63, 1142-1163.

BJORKLUND, D. F., \& HARNiSHFEGER, K. K. (1990). The resources construct in cognitive development: Diverse sources of evidence and a theory of inefficient inhibition. Developmental Review, 10, 48-71.

Brooks, P. J., \& MacWhinney, B. (2000). Phonological priming in children's picture naming. Journal of Child Language, 27, 335-366.

Brooks, P. J., MacWhinney, B., \& Evans, J. (1995, March). Phonological and semantic priming in children's picture naming. Poster presented at the Biennial Meeting of the Society for Research in Child Development, Indianapolis, IN.

Carroll, J. B., Davies, P., \& Richman, B. (1971). The American Heritage word frequency book. Boston: Houghton Mifflin.

Chugani, H., Mazziotta, J. C., \& Phelps, M. E. (1993). Positron emission tomography study of human brain functional development. In M. H. Johnson (Ed.), Brain development and cognition: A reader (pp. 125-143). Malden, MA: Blackwell.

CoHen, J., \& CoHen, P. (1983). Applied multiple regression/correlation analysis for the behavioral sciences. Hillsdale, NJ: Erlbaum.

Cohen, J., MacWhinney, B., Flatt, M., \& Provost, J. (1993). PsyScope: An interactive graphic system for designing and controlling experiments in the psychology laboratory using Macintosh computers. Behavioral Research Methods, Instruments, \& Computers, 25, 257-271.

Comalli, P., Wapner, S., \& Werner, H. (1962). Interference effects of Stroop color word test in childhood, adulthood, and aging. Journal of Genetic Psychology, 100, 47-53.

Cowan, N. (1989). The reality of cross-modal Stroop effects. Perception \& Psychophysics, 45, 87-88.

Cowan, N., \& Barron, A. (1987). Cross-modal, auditory-visual Stroop interference and possible implications for speech memory. Perception \& Psychophysics, 41, 393-401. 
Cowan, N., \& Saults, J. S. (1995). Memory for speech. In H. Winitz (Ed.), Human communication and its disorders (Vol. 4, pp. 81-170). Timonium, MD: York.

DemPSTER, F. N. (1992). The rise and fall of the inhibitory mechanisms: Toward a unified theory of cognitive development and aging. Developmental Review, 12, 45-75.

Diamond, A., \& Taylor, C. (1996). Development of an aspect of executive control: Development of the abilities to remember what I said and to "Do as I say, not as I do." Developmental Psychobiology, 29, 315-334.

Doyle, A. (1973). Listening to distraction: A developmental study of selective attention. Journal of Experimental Child Psychology, 15, 100-115.

Driver, J., \& BAYlis, G. C. (1993). Cross-modal negative priming and interference in selective attention. Bulletin of the Psychonomic Society, 31, 45-48.

EHRI, L. C. (1976). Do words really interfere in naming pictures? Child Development, 47, 502-505.

Elliott, E. M., \& Cowan, N. (2001). Habituation to auditory distractors in a cross-modal, color-word interference task. Journal of Experimental Psychology: Learning, Memory, \& Cognition, 27, 654667.

Elliott, E. M., Cowan, N., \& Valle-Inclan,F. (1998). The nature of cross-modal color-word interference effects. Perception \& Psychophysics, 60, 761-767.

Elliott, L. L., Hammer, M. A., \& Evan, K. E. (1987). Perception of gated, highly familiar spoken monosyllabic nouns by children, teenagers, and older adults. Perception \& Psychophysics, 42, 150157.

Fernald, A., Pinto, J. P., Swingley, D., Weinberg, A., \& McRoberts, G. W. (1998). Rapid gains in speed of verbal processing by infants in the 2nd year. Psychological Science, 9, 228-231.

Gernsbacher, M. A. (1997). Two decades of structure building. Discourse Processes, 23, 265-304.

Gernsbacher, M. A., \& Faust, M. E. (1991). The mechanism of suppression: A component of general comprehension skill. Journal of Experimental Psychology: Learning, Memory, \& Cognition, 17, 245 262.

Gernsbacher, M. A., Varner, K. R., \& Faust, M. E. (1990). Investigating differences in general comprehension skill. Journal of Experimental Psychology: Learning, Memory, \& Cognition, 16, 430-445.

Gerstadt, C. L., Hong, Y. J., \& Diamond, A. (1994). The relationship between cognition and action: Performance of children $31 / 2-7$ years old on a Stroop like day-night test. Cognition, 53, 129-153.

GNYS, J. A., \& WILlis, W. G. (1991). Validation of executive function tasks with young children. Developmental Neuropsychology, 7, 487501.

Green, E. J., \& Barber, P. J. (1981). An auditory Stroop effect with judgments of speaker gender. Perception \& Psychophysics, 30, 459466.

GreEn, E. J., \& BARbER, P. J. (1983). Interference effects in an auditory Stroop task: Congruence and correspondence. Acta Psychologica, 53, 183-194.

HAY S, W. L. (1988). Statistics (4th ed.). Fort Worth, TX: Holt, Rinehart \& Winston.

Jerger, S., Martin, R. C., \& Pirozzolo, F. J. (1988). A developmental study of the auditory Stroop effect. Brain \& Language, 35, 86104.

Jerger, S., Pearson, D. A., \& Spence, M. J. (1999). Developmental course of auditory processing interactions: Garner interference and Simon interference. Journal of Experimental Child Psychology, 74, 44-67.

KaIL, R. (1991). Processing time declines exponentially during childhood and adolescence. Developmental Psychology, 27, 259-266.
KaIL, R. (1992). Processing speed, speech rate, and memory. Developmental Psychology, 28, 899-904.

Lane, D. M., \& Pearson, D. A. (1982). The development of selective attention. Merrill-Palmer Quarterly, 28, 317-337.

Levin, H. S., Culhane, K. A., Hartmann, J., Evankovich, K., Mattson, A. J., Harward, H., Ringholz, G., Ewing-Cobbs, L., \& FLETCHER, J. M. (1991). Developmental changes in performance on tests of purported frontal lobe functioning. Developmental Neuropsychologist, 7, 377-395.

Livesey, D. J., \& Morgan, G. A. (1991). The development of response inhibition in 4- and 5-year-old children. Australian Journal of Psychology, 43, 133-137.

MacLeod, C. M. (1991). Half a century of research on the Stroop effect: An integrative review. Psychological Bulletin, 109, 163-203.

Miles, C., \& Jones, D. M. (1989). The fallacy of the cross-modal Stroop effect: A rejoinder to Cowan (1989). Perception \& Psychophysics, 45, 85-86.

Miles, C., Madden, C., \& Jones, D. M. (1989). Cross-modal, auditoryvisual Stroop interference: A reply to Cowan and Barron. Perception \& Psychophysics, 45, 77-81.

NeILL, W. T. (1977). Inhibitory and facilitatory processes in selective attention. Journal of Experimental Psychology: Human Perception \& Performance, $3,444-450$.

Neill, W. T., \& Westberry, R. L. (1987). Selective attention and the suppression of cognitive noise. Journal of Experimental Psychology: Learning, Memory, \& Cognition, 13, 327-334.

Passler, M. A., IsaAc, W., \& Hynd, G. W. (1985). Neuropsychological development of behavior attributed to frontal lobe functioning in children. Developmental Neuropsychology, 1, 349-370.

Rosinski, R. R., Golinkoff, R. M., \& Kukish, K. S. (1975). Automatic semantic processing in a picture-word interference task. Child Development, 46, 247-253.

SCHILler, P. H. (1966). Developmental study of color-word interference. Journal of Experimental Psychology, 72, 105-108.

Schriefers, H., Meyer, A. S., \& Levelt, W. J. (1990). Exploring the time course of lexical access in language production: Picture-word interference studies. Journal of Memory \& Language, 29, 86-102.

Stroop, J. R. (1935). Studies of interference in serial verbal reactions. Journal of Experimental Psychology, 18, 643-662.

Swingley, D., Pinto, J. P., \& Fernald, A. (1999). Continuous processing in word recognition at 24 months. Cognition, 71, 75-108.

Tipper, S. P., Bourque, T. A., Anderson, S. H., \& Brehaut, J. C. (1989). Mechanisms of attention: A developmental study. Journal of Experimental Child Psychology, 48, 353-378.

Walley, A. C., Michela, V. J., \& Wood, D. R. (1995). The gating paradigm: Effects of presentation format on spoken word recognition by children and adults. Perception \& Psychophysics, 57, 343-351.

Zelazo, P. D., Carter, A., Reznick, J. S., \& Frye, D. (1997). Early development of executive function: A problem-solving framework. Review of General Psychology, 1, 198-226.

Zuckier, H., \& Hagan, J. W. (1978). The development of selective attention under distracting conditions. Child Development, 49, 870873 .

\section{NOTE}

1. For all analyses, we computed effect sizes by using eta-squared, which indicates the proportion of variance accounted for by the effect (Hays, 1988). These effect sizes are provided as percentages of the total variance.

(Manuscript received August 27, 2001; revision accepted for publication July 30,2002 .) 